\title{
Risk factors and causes of stillbirths among pregnant women in Pakistan
}

\author{
Kiran Afshan ${ }^{1}$, Ghulam Narjis², Mazhar Qayyum ${ }^{3}$
}

1. Department of Animal Sciences, Faculty of Biological Sciences, Quaid-i-Azam University Islamabad, 45320, Pakistan.

2. Department of Statistics, Quaid-i-Azam University Islamabad, 45320, Pakistan.

3. Department of Zoology and Biology, Faculty of Sciences, PMAS-Arid Agriculture University, Rawalpindi46300, Pakistan.

\begin{abstract}
Background: Globally 3 million stillbirths occur per year, and Pakistan is ranked $3^{\text {rd }}$ among the countries having the highest burden. Despite being a major public health problem, efforts to reduce this figure are insufficient.

Objective: The aim of the study was to identify and measure the inequalities in stillbirth associated risk factors, causes and fertility risk behaviors.

Methods: Data were derived from the Pakistan Demographic and Health Surveys (PDHS) 1990-2013. Inequalities on determinants were evaluated using rate differences and rate ratios; time trends computed with annualized reduction rate (ARR).

Results: Overall ARR determined for stillbirth was -12.52 percent per annum. The high ARR were recorded for mothers age $<20$, urban areas, educated mothers and for highest wealth quintile. The relative inequalities were most pronounced for wealth quintiles, education and age of mothers. Stillbirth causes were unexplained antepartum (33\%), unexplained intrapartum (21\%), intrapartum asphyxia (21\%) and antepartum maternal disorders $(19 \%)$. The high fertility risk behavior was found in mothers with age $>34$ and birth order $>3$.

Conclusion: The study concluded that to achieve gain in child survival, there is need to promote antenatal care, birth spacing, and family planning programs in developing countries.

Keywords: Perinatal mortality, stillbirth causes, delivery complications, Pakistan.

DOI: https://dx.doi.org/10.4314/ahs.v19i1.24

Cite as: Afshan K, Narjis G, M Q. Risk factors and causes of stillbirths among pregnant women in Pakistan. Afri Health Sci. 2019;19(1). 1507-1516. bttps://dx.doi.org/10.4314/abs.v19i1.24
\end{abstract}

\section{Introduction}

Stillbirths represent a devastating outcome of pregnancy, and 3 million deaths occurred each year during intra-partum period, among these $98 \%$ of cases are from low and middle income countries. ${ }^{1}$ In south Asia over a million of stillbirths occurred in 2008. ${ }^{1}$ Stillbirths are mostly unseen in world health monitoring reports, millennium development goals (MDGs) and countdown to 2015 monitoring

\section{Corresponding author:}

Kiran Afshan,

Department of Animal Sciences, Faculty of Biological Sciences,

Quaid-i-Azam University Islamabad, 45320, Pakistan

Email:kafshan@qau.edu.pk process. $^{2}$ Global burden of disease estimates did not include disability adjusted life-years for perinatal mortality. ${ }^{3}$ The World Health Organisation's defines stillbirth as the numbers with birth weights of $1000 \mathrm{~g}$ or more after 28 weeks of gestation in less developed countries. In developed countries more than third of stillbirths occurred after 22 and before 28 completed weeks of gestation. ${ }^{4}$ but are hardly estimated in low-income countries. ${ }^{1,5}$

In Pakistan, stillbirth rate is 32 per thousand deliveries, ${ }^{6}$ with estimated number of 167,040 stillbirths in the year 2012 based on total population (180 million) of Pakistan and expected number of deliveries $(2.9 \%){ }^{7,8}$ The direct medical causes of stillbirths are documented as: congenital abnormalities, ante-partum haemorrhage, infection, prematurity, maternal accident, prolonged labour, cord 
prolapse and malpresentation. Some of these direct medical causes are indicative of poor quality of care of services, clinical error and medical negligence. ${ }^{9}$ In Pakistan at the community level, nearly two-third of deliveries continue to take place at home with more than $62 \%$ of all deliveries assisted by untrained birth attendants. ${ }^{10}$ Hence, in a substantial number of cases the exact cause of stillbirth remains unconfirmed with the communities explaining stillbirths according to socio-cultural and religious beliefs.

The governmental health departments in low and middle income countries do not record stillbirths; it is surely overlooked by funding bodies, policy makers, and local communities. In Pakistan, despite considerable initiatives undertaken over decades progress with respect to maternal and neonatal health indicators remains poor, and country remained clearly 'off track' to reach the set targets of MDGs 2015.11 In post 2015 era to reduce the stillbirths new targets were set for the countries within the agenda of the Lancet Commission on Investing in Health and the Sustainable Development Goals (SDGs) to be met by 2035 and $2030 .^{12,13}$ These targets include less than 10 stillbirths per 1000 total births by $2035 .{ }^{12}$ To complete the set targets and end the preventable perinatal deaths, considerable efforts are required.

In Pakistan, due to slow progress in child survival programs and to achieve new targets, there is need to comprehend the determinants of stillbirths. To determine the best performance scenario, we calculated the average annual rate of reduction for risk factors associated with stillbirths in Pakistan by using data from three national surveys. The objectives of this study are also to measure relative and absolute socio-economic and demographic inequalities in stillbirths over time.

\section{Methods}

\section{Data source}

Data used in present study were obtained from three national surveys conducted in 1990-1991, 2006-2007 and 2012-2013 to calculate perinatal mortality, its causes and high risk fertility behaviour across Pakistan. The registration system of Pakistan is incomplete and stillbirth rates were figured form household surveys (Pakistan Demographic and Health Surveys, PDHS). The study protocol does not raise any ethical issues; all data are freely avail- able from the MEASURE DHS website (www.measuredhs.com).

PDHS 1990-191 used three types of questionnaires, the Household Questionnaire, the Woman's Questionnaire and the Husband's Questionnaire, formatted on DHS Model B Questionnaire developed for countries with low contraceptive use. The two-stage stratified sampling technique was applied in survey and recorded response rate was $96 \%$ for women and 78\% for men. In 2006-2007 PDHS six types of questionnaires were used namely: the Community, the Short Household, the Long household, the Women's, the Maternal Verbal Autopsy, and the Child Verbal Autopsy Questionnaires, formatted on model questionnaires developed by the Measure DHS program. A two stage-stratified cluster random sampling method was designed in the survey with a total response rate 98\%. The PDHS 2012-2013 selected four types of questionnaires: Household Questionnaire, Woman's Questionnaire, Man's Questionnaire, and Community Questionnaire, with two-stage stratified sample design. The response rate recorded was $93 \%$ in women and $79 \%$ in men. In all three surveys verbally informed consent was taken and trained enumerators were selected to assemble information from households and respondents. The comprehensive detail on contents of questionnaires, sampling methodologies are available separately in three national PDHS.

The information on the causes of stillbirth was obtained from mothers of deceased children, doctors and from health care workers during the 1990-2013 PDHS. The standard infant and child verbal autopsy (VA) questionnaire ${ }^{14}$ were used, and a panel consensus with computer allocation and manual assessments was applied to decide the ultimate cause of demise. The International Classification of Diseases (ICD 10) coding system was used to assign the final cause of death.

\section{Model selection and uncertainty estimation}

This study assess the determinants of stillbirths rates, represented as deaths per 1,000 live births. The variables evaluated in current study from above mentioned three surveys data were: place of residence, education of mothers, wealth quintiles and age of mothers at birth, maternal fertility behaviour in term of single and multiple risk 
categories. Bivariate logistic regression analysis was performed and adjusted odds ratios (OR) with 95\% CI were calculated. Level of significance was set at $\mathrm{p}<0.05$.

To calculate the magnitude and trends in inequalities, rate differences (highest- lowest) as absolute measures of inequality and rate ratios (highest/lowest) as relative measures of inequality for 2006-2007and 2012-2013 PDHS were computed. The rate ratio is unit less and independent of average levels and scale, whereas the rate difference depends on both average levels and scale. ${ }^{15-17}$

The annual rate of reduction is applied to calculate the trends in increase (e.g. improved coverage) or decrease (e.g. reduced rate) in mortality rates, and to create pro- jections of rates into the future. The annual rate of reduction (ARR) in perinatal mortality for this study was calculated as:

Where $\mathrm{LN}$ is the natural logarithm, PMR is the perinatal mortality rate, and $t 0$ and $\mathrm{t} 1$ correspond to base year and current year respectively. ${ }^{18}$ The statistical analyses were calculated by using Microsoft Excel version 10 and SPSS V. 17.

\section{Results}

\section{Perinatal mortality rate}

The change in perinatal mortality along its critical determinants age of mothers at birth, residence, education of mothers and wealth quintiles are given in table 1 for two national surveys 2006-2007 and 2012-2013.

Table 1: Stillbirth determinants with rate difference, rate ratios and annual rate of reduction from the data obtained from two national surveys.

\begin{tabular}{|c|c|c|c|c|c|c|c|c|c|}
\hline \multirow[t]{2}{*}{ Characteristic } & \multirow[t]{2}{*}{ 2006-07 } & \multirow[t]{2}{*}{ 2012-13 } & \multirow{2}{*}{$\begin{array}{l}\text { Annual Rate of } \\
\text { reduction } \\
(2006-2013)\end{array}$} & \multicolumn{3}{|c|}{ 2006-07 } & \multicolumn{3}{|c|}{ 2012-2013 } \\
\hline & & & & Estimated $(\beta)$ & Adj. OR (CI 95\%) & $p$ value & $\begin{array}{c}\text { Estimated } \\
(\beta)\end{array}$ & Adj. OR (CI 95\%) & $p$ value \\
\hline \multicolumn{10}{|l|}{$\begin{array}{c}\text { Age of Mother at } \\
\text { birth }\end{array}$} \\
\hline$<20$ & 197 & 104 & -10.65 & -0.186 & $0.8307(0.6702-1.0297)$ & 0.0904 & -0.23 & $0.7979(0.6058-1.0509)$ & 0.1081 \\
\hline $20-29$ & 145 & 65 & -13.37 & -0.555 & $0.5742(0.4563-0.7226)$ & $0.0000 * * *$ & -0.74 & $0.4779(0.3495-0.6534)$ & $0.0000 * * *$ \\
\hline $30-39$ & 161 & 84 & -10.84 & -0.431 & $0.6498(0.5193-0.8130)$ & $0.000164 * * *$ & -0.46 & $0.6304(0.4713-0.8431)$ & $0.00187 * *$ \\
\hline $40-49$ & 228 & 127 & -9.75 & & 1 & & & 1 & \\
\hline rate difference & 83 & 62 & na & & & & & & \\
\hline rate ratio & 1.57 & 1.95 & na & & & & & & \\
\hline \multicolumn{10}{|l|}{ Residence } \\
\hline Rural & 153 & 85 & -9.8 & -0.147 & $0.8635(0.6805-1.0945)$ & 0.226 & 0.55 & $1.7285(1.2121-2.4885)$ & $0.0028 * *$ \\
\hline Urban & 173 & 51 & -20.36 & & 1 & & & 1 & \\
\hline rate difference & 20 & 34 & na & & & & & & \\
\hline rate ratio & 1.13 & 1.67 & na & & & & & & \\
\hline \multicolumn{10}{|c|}{ Education of Mothers } \\
\hline No education & 158 & 87 & -9.94 & 0.101 & $1.1065(0.8663-1.4132)$ & 0.4176 & 0.91 & $2.4801(1.6705-3.6822)$ & $0.00000 * * *$ \\
\hline Primary & 154 & 70 & -13.14 & 0.071 & $1.0734(0.8394-1.3726)$ & 0.5725 & 0.67 & $1.9590(1.3021-2.9473)$ & $0.00125 * *$ \\
\hline Middle & 169 & 64 & -16.18 & 0.182 & $1.1992(0.9419-1.5268)$ & 0.1405 & 0.58 & $1.7796(1.1756-2.6941)$ & $0.00644 * *$ \\
\hline Secondary & 173 & 54 & -19.41 & 0.210 & $1.2335(0.9698-1.5689)$ & 0.0872 & 0.40 & $1.4857(0.9686-2.2789)$ & 0.06972 \\
\hline Higher & 145 & 37 & -22.76 & & 1 & & & 1 & \\
\hline rate difference & 28 & 50 & na & & & & & & \\
\hline rate ratio & 1.19 & 2.35 & na & & & & & & \\
\hline \multicolumn{10}{|l|}{ Wealth quintile } \\
\hline Lowest & 138 & 101 & -5.2 & -0.253 & $0.7761(0.6083-0.9903)$ & $0.0415 *$ & 0.85 & $2.33(1.6250-3.3408)$ & $0.00000 * * *$ \\
\hline Second & 178 & 86 & -12.12 & 0.049 & $1.0498(0.8333-1.3226)$ & 0.6801 & 0.67 & $1.9514(1.3488-2.8232)$ & $0.000389 * * *$ \\
\hline Middle & 151 & 69 & -13.05 & -0.148 & $0.8622(0.6790-1.0949)$ & 0.2239 & 0.43 & $1.5371(1.0471-2.2563)$ & $0.028165 *$ \\
\hline Fourth & 158 & 62 & -15.59 & -0.095 & $0.9097(0.7180-1.1525)$ & 0.4331 & 0.32 & $1.3708(0.9263-2.0285)$ & 0.114708 \\
\hline Highest & 171 & 46 & -21.88 & & 1 & & & 1 & \\
\hline rate difference & 40 & 55 & & & & & & & \\
\hline rate ratio & 1.29 & 2.2 & & & & & & & \\
\hline Total & 159 & 75 & -12.52 & & & & & & \\
\hline
\end{tabular}


The data on associated risk factors of stillbirth was not generated in 1990-1991 PDHS. The annual reduction rate in stillbirth is recorded -12.52 percent per annum. The progress in perinatal mortality was recorded for all associated risk factors from 2006-2013. The annual reduction rate recorded for mothers age $<20$ is -10.65 percent per annum, with $40-49$ is -9.75 percent per annum. The annual reduction rate was recorded in urban (-20.36 percent per annum), rural (-9.80 percent per annum), uneducated mothers (-9.94 percent per annum), educated mothers (-22.76 percent per annum) and in lowest ( -5.20 percent per annum), second (-12.12 percent per annum) and highest (-21.88 percent per annum) wealth quintiles. The rate difference (55) and relative inequalities (2.2) are most pronounced for wealth quintiles and mothers education (with rate difference 50 and rate ratio 2.35 for uneducated mothers compared with higher education). The mother's age at birth has rate difference 62 and inequalities 1.95 for 40-49 compared with 20-29 years. The bivariate logistic regression analysis for perinatal mortality showed a significant $(\mathrm{p}<0.05)$ association with residence (Adj OR= $1.72895 \% 1.21-2.49)$ for 2012-13 survey. In both survey periods, age of mothers at birth 20-29 (Adj OR=0.574 95\% CI 0.456-0.72; Adj OR=0.477 95\% CI 0.349-0.653) and 30-39 years (Adj OR=0.649 95\% CI 0.519-0.813; Adj OR $=0.630$ 95\% CI 0.471-0.843) showed significant $(\mathrm{p}<0.05)$ high risk of perinatal mortality. A significant $(p<0.05)$ association was observed between perinatal mortality and uneducated (Adj OR $=2.48095 \%$ CI 1.6703.682), primary (Adj OR=1.959 95\% CI 1.302-2.947) and secondary (Adj OR= 1.779 95\% CI 1.175-2.694) education mothers for 2012-2013. In 2012-2013 survey a highly significant $(\mathrm{p}<0.01)$ association was recorded for lowest (Adj OR=2.33 95\% CI 1.6250-3.340), second (Adj OR=1.951 95\% CI 1.348-2.82) and middle (Adj $\mathrm{OR}=1.537$ 95\% CI 1.047-2.256) wealth quintiles.

\section{Causes of perinatal mortality}

The causes of perinatal mortality from 1990-2013 survey periods are shown in figure 1 . The intrapartum and antepartum complications are major causes of stillbirth

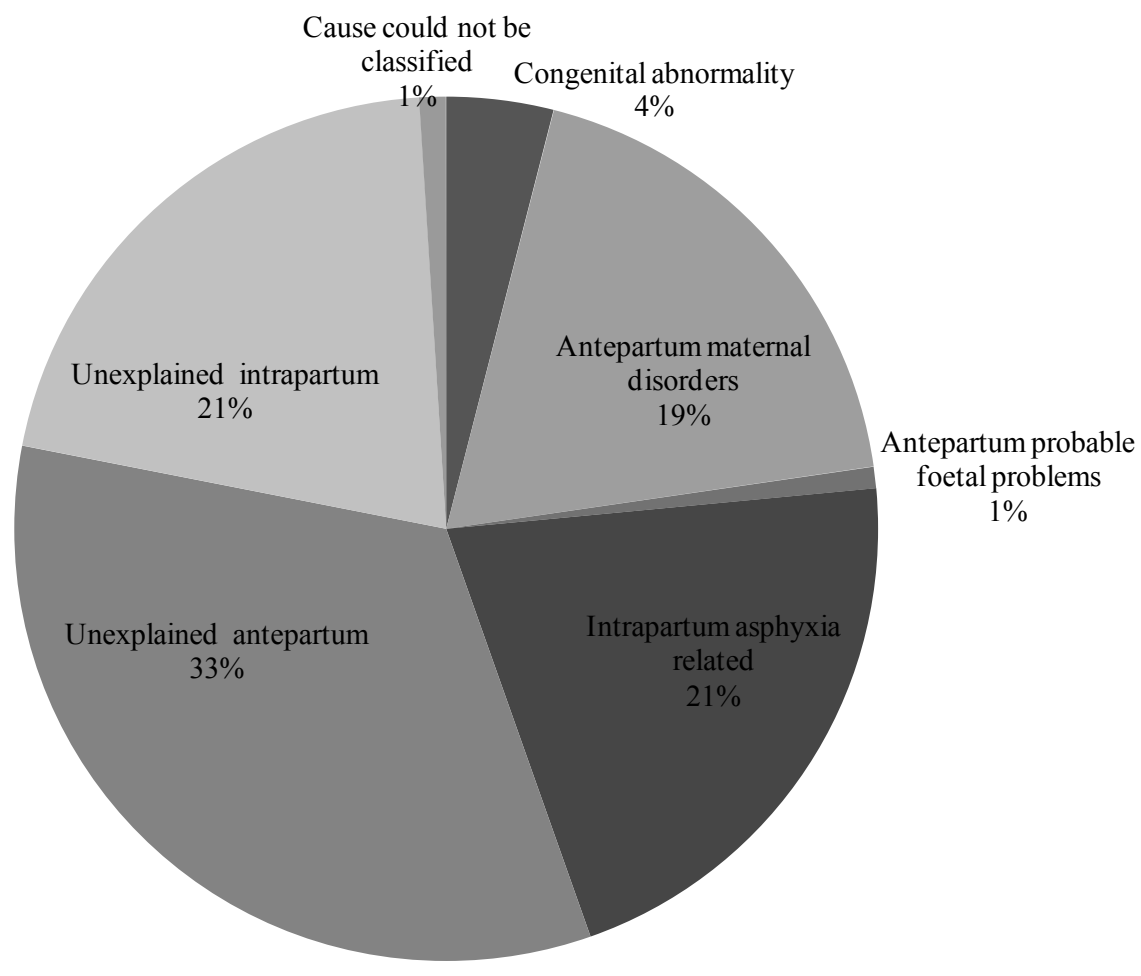

Figure1: Causes of Stillbirth reported in national surveys of Pakistan 2006-2013. 


\section{High-risk fertility behaviour}

Several demographic reports have directed that the survival chances of children are dependent on fertility pattern of her mothers. In current analysis, the variables are defined as young mothers with age group $<18$, Old mothers with age more than 34 , birth interval less than 24 months and birth order more than 3 children. The birth percentages in six year preceding the survey by various risk categories in three national surveys are shown in figure 2 . The births fall into any single high risk category were found to be $55 \%$ (1990-1991), 38\% (2006-2007) and 37\% (2012-2013) for three national surveys. The major single high risk categories reported were age of mothers $>34$, birth order $>3$ and birth interval $<24$ months. Births fall in multiple risk category were recorded $19 \%$, $24 \%$ and $21 \%$ respectively for three surveys from 1990 2013 PDHS.
The birth percentages in currently married women along with risk category are shown in figure 2 . The data collected during three national surveys identified sterilized women not being in any risk category, who were found engaged in family planning activities by using different contraceptive methods and with prolonged abstinence. The high multiple risk category was found age $>34$ and birth order $>3$ with $20.8 \%$ for 1990-1991 PDHS, $42 \%$ for 2006-2007 PDHS, and 39\% for 2012-2013 national survey. The single high risk category of birth interval < 24 months and birth order $>3$ were recorded in currently married women for three surveys. The currently married women falls in high single risk category was recorded $17.2 \%$ for 1990-1991 PDHS and 30\% for 2006-2007, and 2012-2013 national surveys.

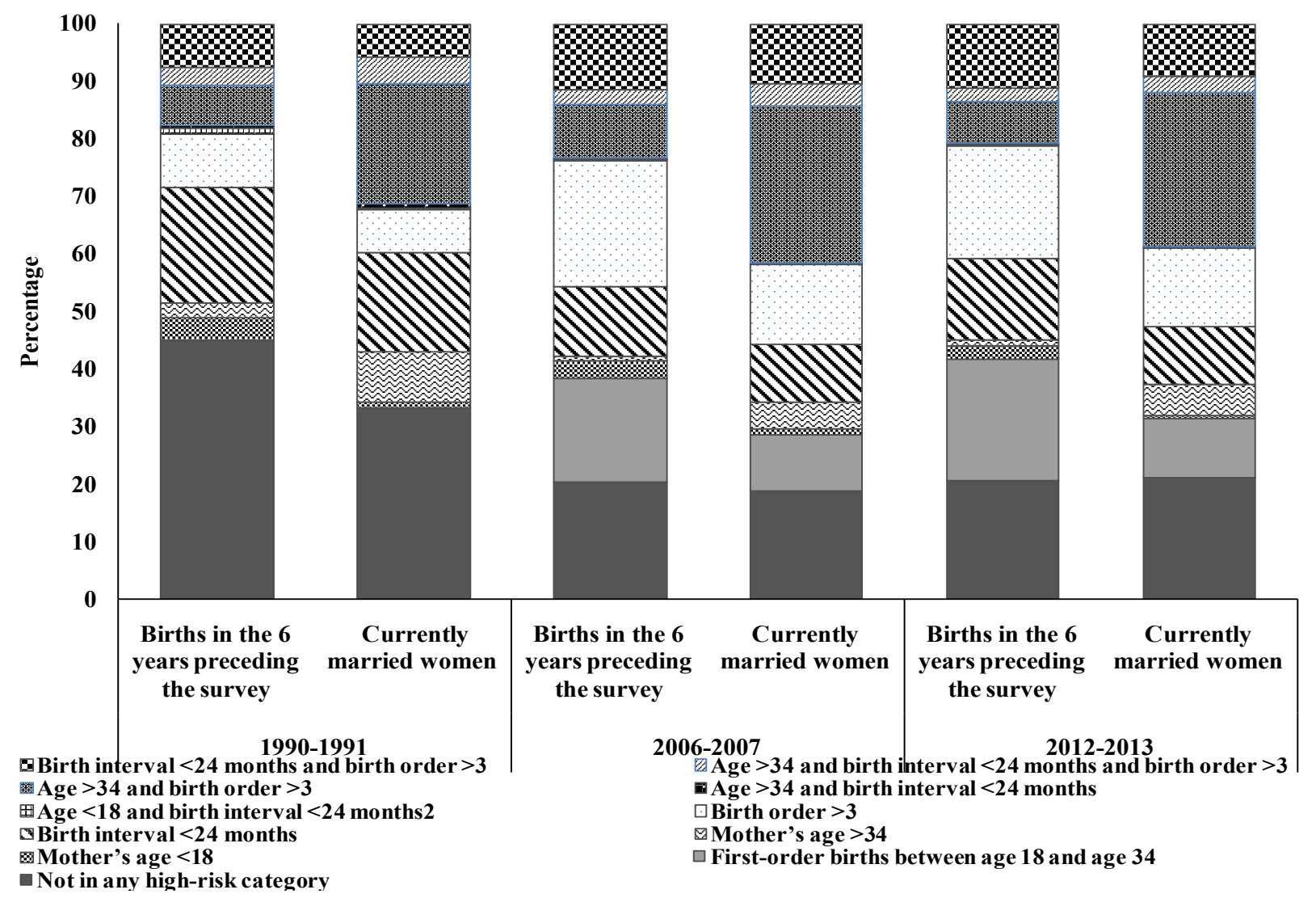

Figure 2: Birth percentages among women in six years preceding the survey and currently married women, who were to conceive a child at the time of survey by various risk categories from the data obtained from three national surveys. 


\section{Discussion}

Stillbirth is a major but often neglected public health issue. The population based data derived from national surveys of country allowed us to assess risk categories of stillbirth that will require further investigation in future studies. The current findings indicated high stillbirth rates in Pakistan and identified the risk categories which were uneducated women, those who have lowest wealth quintiles, old age and those who are living in remote areas where they did not have access to any health services, as previously reported. ${ }^{19-23}$ The development and implementation of number of maternal and child health programs at national level to date do not have significant role in increase or decrease of inequalities, and annualized reduction rate has not pronounced decline to reach the set targets for 2035 .

Comparing stillbirth rates with risk factors shows that most of the variables did not significantly associated in 2006-2007 survey period, while for 2012-2013 survey these variables are significantly associated. One of the reasons of this contrary in the result of both surveys stillbirth rate may because of high degree of sampling variation and differences by background characteristics. The 2006-2007 PDHS did not include an event "calendar" for recording the pregnancy losses that had occurred in the five years preceding the survey, while it had been recorded for 2012-2013 PDHS.

The relative inequalities in perinatal mortality increases between wealth quintile and education of mothers for the 2012-2013 survey periods compared to 2006-2007. This increase leads to reduction in stillbirth with improvement in wealth quintiles and education of mother. The results showed that stillbirth rate significantly differ between lowest wealth quintiles, uneducated, older aged mothers and those living in deprived areas. The socio-economic status of mother is one of the major risk factor of stillbirth, reflects with reports from developing countries. ${ }^{14,25-30}$ In India several studies had reported significant association of wealth status with stillbirth. ${ }^{31,32}$ A study conducted in five developing countries recorded lack of formal education increases the relative risk of stillbirths. ${ }^{33}$ Other studies in Nigeria, recorded statistically significant association between uneducated mothers and stillbirth. ${ }^{34} \mathrm{~A}$ number of reports from Ghana and Brazil recorded signification association between uneducated poor mothers and stillbirth. ${ }^{31,35-40}$

The uneducated mother with lowest wealth quintiles has about two-fold risk of perinatal deaths as compared to educated mothers with high wealth quintiles. Existing evidence supports the fact that overall health seeking behavior of the more educated mother is much better than those of parturient with low levels of education or no formal education, as recorded in previous studies. ${ }^{41-43}$ Education tends to minimize the challenges of low socioe-conomic status and lack of knowledge amongst the females. $^{41,44}$

The Government of Pakistan and many international donors have implemented various programs to improve mother and child health. Considerable policy change occurred in the last decade by adding newborns care into existing community-based maternal and child packages delivered by the Lady Health Worker Program. National Maternal, Newborns and Child Health (MNCH) Communication Strategy Framework were developed under the MNCH Program. ${ }^{45}$ The U.S. Agency for International Development (USAID) funded project Pakistan Initiative for Mothers and Newborns (PAIMAN) results reported significant reductions instillbirth. ${ }^{46}$ The implementation of these programs in the country by using large financial and personnel resources will be helpful to improve the newborns survival and will be important to sensibly assess their future performance in terms of coverage and effectiveness. A combination of challenges has prevented progress, such as humanitarian disaster and political instability, policy to programme gaps and demand/supply barriers like geographic and socio-cultural obstacles that prevent care seeking. ${ }^{47}$

Despite the number of programs that have been initiated in the country to reduce stillbirth rate, Pakistan was reported as worst performer out of 186 countries having highest rate of stillbirths at the end of year $2015 .^{45}$ The perinatal deaths in Pakistan are 43.1 per 1,000 total births a rate higher than that compared to global rate (18.4 stillbirths per 1000 total births). ${ }^{45}$ Although worldwide stillbirth rates have decreased slightly, the average annual rate of reduction (ARR) of stillbirths $(2.0 \%)$ has been far slower than that for either maternal $(3.0 \%)$ or post-neonatal mortality of children younger than 5 years $(4.5 \%) .{ }^{45}$ 
The major causes of stillbirth identified in national surveys were unexplained antepartum (33\%), unexplained intrapartum (21\%), intrapartum asphyxia (21\%) and antepartum maternal disorders (19\%). The findings are in accordance with developed countries having high socio-economic status and health services. The risk factors for antepartum stillbirth reported in previous studies are absence of pre-birth care, hemorrhage, hypertensive disorder, and small-for-gestational age babies. ${ }^{19-21,23}$ Several studies conducted to identify causes of perinatal deaths reported 3.1-25\% were due to intrapartum and trauma. ${ }^{48,49}$ In Tanzania asphyxia-related causes $(25 \%),{ }^{49}$ intrauterine asphyxia $(21 \%)$ in Thailand ${ }^{50}$ and intrauterine asphyxia $(16.7 \%)$ in West Bengal. ${ }^{48}$ Similarly to present investigation, previous studies recorded $3.8-57.4 \%$ of perinatal mortality were unclassifiable with unknown causes. ${ }^{51,52}$ In Bangladesh (49\%)and Nepal (47\%) half of the all perinatal mortalities are reported with unknown causes. ${ }^{12,53}$ Similarly in Nigeria $(38.8 \%)^{54}$ and India $(18 \%)^{25}$ causes of perinatal deaths were unidentified. A study conducted in Ghana recorded unexplained causes of antepartum $(57.4 \%)$ and intrapartum $(31.5 \%)$ deaths. ${ }^{51}$ Nevertheless, the identification of causes of perinatal mortalities for number of cases are never been established. ${ }^{51,55,56}$ Moreover, majority of these factors are preventable and focused efforts on part of health care providers are required. ${ }^{57}$

The present results indicated mothers with birth interval less than 24 months, birth order more than 3 , age of mothers $>34$ and $<18$ are at high risk category, which are in agreement with other reported studies. ${ }^{58-60}$ Only a few studies have examined the risks of older maternal age on birth outcomes by parity. ${ }^{61-64}$ In contrast to present findings no differential effect of parity on the risk of stillbirth in older mothers was recorded. ${ }^{62-63,65}$ The healthy timings and spacing of pregnancies initiative ${ }^{66}$ should be measured as a precedence in Pakistan because of its importance for mothers and newborns health; hence the role health care providers in promoting health interventions is needed. The areas with high stillbirths and poor health services strategies should target the peri-partum period for maximal reduction. ${ }^{1}$ The current results can be useful for designing appropriate interventions that will improve obstetric practices and reduce the enormity stillbirth burden in Pakistan.

\section{Conclusion}

Stillbirths vary significantly by socio-demographic variables. The current results concluded that in order to achieve gain in child survival there is dare need to promote antenatal care, birth spacing and family planning programs. The development of clear guidelines, suitable classification system to assign causes of death, training of health care personnel to solve complications during parturition in developing countries is required.

\section{Conflict of interest}

The authors declared no potential conflicts of interest with respect to the research, authorship, and/or publication of this article.

\section{Funding}

None.

\section{Research Ethics Committee}

The study protocol does not raise any ethical issues; all data are freely available from the MEASURE DHS website (www.measuredhs.com).

\section{Author's contribution}

$\mathrm{KA}, \mathrm{GN}$ and MQ designed the study. GN and KA carried search, data analysis and manuscript preparation. MQ advised on methods and interpretation of findings. MQ reviewed the manuscript. All authors have participated in the study and concur with the submission and subsequent revisions submitted the corresponding author.

\section{References}

1. Lawn J, Blencowe H, Pattinson R, et al. Stillbirths: Where? When? Why? How to make the data count? Lancet. 2011; 377:1448-63.

2. World Health Organization, UNICEF. Countdown to 2015 decade report (2000-2010): taking stock of maternal, newborn and child survival. Geneva: WHO; 2010. 3. Murray CJL, Lopez AD, editors. The global burden of disease: a comprehensive assessment of mortality and disability from diseases, injuries, and risk factors in 1990 and projected to 2020. Cambridge: Harvard University Press; 1996.

4. Flenady V, Middleton P, Smith GC, et al. The Lancet's Stillbirths Series steering committee. Stillbirths: the way forward in high-income countries. Lancet. 2011; published online April 14. DOI:10.1016/S0140-6736(11)60064-0. 
5. Froen JF, Gordijn SJ, Abdel-Aleem H, et al. Making stillbirths count, making numbers talk-issues in data collection for stillbirths. BMC Pregnancy Childbirth. 2009; 9: 58.

6. McClure EM, Pasha O, Goudar SS, Chomba E, Garces A, Tshefu A, et al. Epidemiology of stillbirth in low-middle income countries: a Global Network Study. Acta obstetricia et gynecologica Scandinavica. 2011;90:1379-85.

7. UNFPA. State of world population 2013 - Motherhood in Childhood: Facing the challenge of adolescent pregnancy. United Nation's Population Fund; 2013.

8. Ministry of Health. ProceduresManual For District Health Information System (DHIS). Islamabad: National Health Information Resource Center (NHIRC), Ministry of Health, Pakistan; 2009.

9. Oyebode F. Clinical errors and medical negligence. $A d-$ vances Psychiatr Treatment. 2006; 12: 221-7. PubMed.

10. National Institute of Population Studies. Pakistan Demographic and Health Survey 2006-07. Ministry of Population Welfare, Government of Pakistan; 2007.

11. The Partnership for Maternal Newborn \& Child Health. Analysing Commitments to Advance the Global Strategy for Women's and Children's Health: The PMNCH 2011 Report. Geneva: 2011.

12. WHO. World Health Assembly closes. Geneva: World Health Organization, 2014. http://www.who.int/mediacentre/news/releases/2014/WHA-20140524/en/ (accessed Sept 25, 2014).

13. Jamison DT, Summers LH, Alleyne G, et al. Global health 2035: a world converging within a generation. Lancet. 2013; 382: 1898-955. PubMed.

14. Anker M, Black RE, Coldham C, Kalter H, Quigley MA, Ross D, Snow RW. A standard verbal autopsy method for investigating causes of death in infants and children. Geneva: World Health Organization; 2008.

15. Evans T, Whiteheard M, Diderichsen F, Bhuiya AMW. Measuring disparities in Health: methods and indicators. In Challanging Inequalities in health, from ethics to action. New York: Oxford University Press; 2001:49-67.

16. Houweling TA, Kunst AE, Huisman M, Mackenbach JP. Using relative and absolute measures for monitoring health inequalities: experiences from cross-national analyses on maternal and child health. Int J Equity Health. 2007; 6:15.

17. Moser K, Frost C, Leon DA. Comparing health inequalities across time and place-rate ratios and rate differ- ences lead to different conclusions: analysis of cross-sectional data from 22 countries 1991-2001. Int J Epidemiol. 2007; 36(6):1285-1291.

18. Liu L, Johnson HL, Cousens S, Perin J, Scott S, Lawn JE, Rudan I, Campbell H, Cibulskis R, Li M, et al. Global, regional, and national causes of child mortality: an updated systematic analysis for 2010 with time trends since 2000. Lancet. 2012; 379(9832):2151-2161.

19. Getahun D, Ananth CV, Kinzler WL. Risk factors for antepartum and intrapartum stillbirth: a population-based study. Am J Obstet Gynecol. 2007;196(6):499-507.

20. Evers AC, Nikkels PG, Brouwers HA, Boon J, van Egmond-Linden A, Hart C, et al. Substandard care in antepartum term stillbirths: prospective cohort study. Acta Obstet Gynecol Scand. 2011;90(12):1416-22.

21. Flenady V, Koopmans L, Middleton P, Froen JF, Smith GC, Gibbons K, et al. Major risk factors for stillbirth in high-income countries: a systematic review and meta-analysis. Lancet. 2011;377(9774):1331-40.

22. Mavalankar DV, Trivedi CR, Gray RH. Levels and risk factors for perinatal mortality in Ahmedabad, India. Bull World Health Organ. 1991;69(4):435-42.

23. Ashish KC, Nelin V, Wrammert J, Ewald U, Vitrakoti R, Baral GN, Målqvist M. Risk factors for antepartum stillbirth: a case-control study in Nepal. BMC Pregnancy and Childbirth. 2015;15:146.

24. Di Mario S, Say L, Lincetto O. Risk factors for stillbirth in developing countries: a systematic review of the literature. Sex Transm Dis. 2007;34:S11-21.

25. Engmann C, Walega P, Aborigo RA, Adongo P, Moyer CA, Lavasani L, et al. Stillbirths and early neonatal mortality in rural Northern Ghana. Trop Med Int Health. 2012;17:272-82. PubMed.

26. Cripe SM, Phung TT, Nguyen TPL, Williams MA. Risk factors associated with stillbirth in Thai Nguyen Province, Vietnam. J Trop Pediatr. 2007;53:66-7. PubMed. 27. Lee AC, Mullany LC, Tielsch JM, Katz J, Khatry SK, Leclerq SC, et al. Community-based stillbirth rates and risk factors in rural Sarlahi, Nepal. Int J Gynaecol Obstet. 2011;113:199-204.

28. Graner S, Klingberg Allvin M, Phuc HD, Krantz G, Mogren I. The panorama and outcomes of pregnancies within a well-defined population in rural Vietnam 19992004. Int J Behav Med. 2009;16:269-77. PubMed.

29. Bell JS, Ouédraogo M, Ganaba R, Sombie I, Byass P, Baggaley RF, et al. The epidemiology of pregnan- 
cy outcomes in rural Burkina Faso. Trop Med Int Health. 2008;13:31-43. PubMed.

30. Katz JK, Khatry SK, LeClerq SC, Shrestha SR, West KP Jr, Christian P. Miscarriage but not stillbirth rates are higher among younger nulliparas in rural Southern Nepal. J Adolescent Health. 2008;42:587-95. PubMed.

31. Williams EK, Hossain MB, Sharma RK, Kumar V, Pandey CM, Baqui AH. Birth interval and risk of stillbirth or neonatal death: findings from rural north India. J Trop Pediatr. 2008; 54:321-7. PubMed.

32. Bhattacharyya R, Pal A. Stillbirths in a referral medical college hospital, West Bengal, India: A ten-year review. $J$ Obstet Gynaecol Res. 2012; 38:266-71. PubMed.

33. McClure EM, Wright LL, Goldenberg RL, Goudar SS, Parida SN, Jehan I, et al. The global network: a prospective study of stillbirths in developing countries. Am J Obstet Gynecol. 2007;197:247. e1-5. PubMed.

34. Mutihir JT, Eko P. Stillbirths at the Jos University Teaching Hospital: incidence, risk, and etiological factors. Niger J Clin Pract. 2011;14:14-18. PubMed.

35. McClure EM, Pasha O, Goudar SS, Chomba E, Garces A, Tshefu A, et al. Epidemiology of stillbirth in low-middle income countries: a Global Network Study. Acta Obstet Gynecol Scand. 2011; 90:1379-85.

36. Engmann C, Walega P, Aborigo RA, Adongo P, Moyer CA, Lavasani L, et al. Stillbirths and early neonatal mortality in rural Northern Ghana. Trop Med Int Health. 2012; 17:272- PubMed ;82.

37. Assaf S, Khawaja M, DeJong J, Mahfoud Z, Yunis K. Consanguinity and reproductive wastage in the Palestinian Territories. Paediatr Perinat Epidemiol. 2008; 23:107-15. 38. Nankabirwa V, Turnwine JK, Tyllesk€ar T, Nankunda J, Sommerfelt H. Perinatal mortality in eastern Uganda: a community based prospective cohort study. PLoS One. 2011; 6:e19674.

39. Cherry N, Shaikh K, McDonald C, Chowdhury Z. Stillbirth in rural Bangladesh: arsenic exposure and other etiological factors: a report from Gonoshasthaya Kendra. Bull World Health Organ. 2008; 86(3):172-7.

40. Andrade LG, Amorim MM, Cunha A, Leite SR, Vital SA. Fatores associados anatimortalidade em uma maternidade escola em Pernambuco: estudo caso-controle (Factors associated with stillbirth in a school maternity in Pernambuco: a case control study). Rev Bras Ginecol Obstet. 2009; 31:285-92. PubMed.

41. Harrison KA. Child bearing, health and social pri- orities: A survey of 22774 consecutive hospital births in Zaria, Northern Nigeria. Br J Obstet Gynaecol. 1985; 92(Suppl. 5):1 119.

42. Shaikh BT, Hatcher J. Health seeking behaviour and health service utilization in Pakistan: Challenging the policy makers. J Public Health (Oxf). 2005; 27: 4954.

43. Ghosh N, Chakrabarti I, Chakraborty M, Biswas R. Factors affecting the healthcare seeking behavior of mothers regarding their children in a rural community of Darjeeling district, West Bengal. Int J Med Public Health. 2013; 3:12 6.

44. Mutihir JT, Eka PO. Stillbirths at the Jos University Teaching Hospital: Incidence, risk, and etiological factors. Niger J Clin Pract. 2011; 14:14 8.

45. The Lancet Ending preventable stillbirths Series 2016: http://www.thelancet.com/ series/ending-preventable stillbirths

46. Mahmood, A. 2010. Improving maternal and neonatal health: measuring the impact of the PAIMAN Project in ten districts in Pakistan, comparing baseline and end line household survey findings (2005-2010). http://www. popcouncil.org/pdfs/2010PAIMAN_EndlineReport. pdf

47. Khan, A, Kinney MV, Hazir T, Hafeez A, Wall SN, Ali N, Lawn JE, Badar A, Khan AA, Uzma Q, Bhutta ZA. Newborn Survival in Pakistan: a decade of change and future implications. Pakistan Newborn Change and Future Analysis Group. Health Policy and Planning. 2012; 27(Suppl. 3): iii72-87.

48. Bhattacharyya R, Pal A. Stillbirths in a referral medical college hospital, West Bengal, India: A ten-year review. J Obstet Gynaecol Res. 2012; 38:266-71. PubMed.

49. Hinderaker SG, Olsen BE, Bergsjø PB, Gasheka P, Lie RT, Havnen J, et al. Avoidable stillbirths and neonatal deaths in rural Tanzania. BJOG. 2003; 110:616-23. PubMed.

50. Mo-suwan L, Isaranurug S, Chanvitan P, Techasena W, Sutra S, Supakunpinyo C, et al. Perinatal death pattern in the four districts of Thailand: findings from the Prospective Cohort Study of Thai Children (PCTC). J Med Assoc Thai. 2009; 92:660-6. PubMed.

51. Edmond KM, Quigley MA, Zandoh C, Danso S, Hurt C, Agyei SO, et al. Aetiology of stillbirths and neonatal deaths in rural Ghana: implications for health programming in developing countries. Paediatr Perinat Epidemiol. 2008;22:430-7. PubMed. 
52. Taweevisit M, Thorner PS. Hydrops fetalis in the stillborn: a series from the central region of Thailand. Pediatr Dev Pathol. 2010;13:369-74. PubMed.

53. Manandhar SR, Manandhar MR, Baral MR, Pandey S, Padhey S. One year audit of perinatal mortality at Kathmandu Medical College Hospital. Kathmandu Uni Med J. 2003;2:198-202.

54. Kuti O, Owolabi AT, Orji EO, Ogunlola IO. Antepartum fetal death in a Nigerian teaching hospital: aetiology and risk factors. Trop J Obstet Gynaecol 2003;20:134-6. 55. McClure EM, Nalubamba-Phiri M, Goldenberg RL. Stillbirth in developing countries. Int J Gynaecol Obstet. 2006;94:82-90.

56. Baqui A, Choi Y, Williams E, Arifeen S, Mannan I, Darmstadt G, et al. Levels, timing, and etiology of stillbirths in Sylhet district of Bangladesh. BMC Pregnancy Childbirth. 2011;11:25.

57. Cockerill R, Whitworth MK, Heazell AE. Do medical certificates of stillbirth provide accurate and useful information regarding the cause of death? Paediatr Perinat Epidemiol. 2012; 26:117-23.

58. Gardosi J, Madurasinghe V, Malik A, Francis A. Maternal and fetal risk factors for stillbirth: population based study. BMJ. 2013;346:f108 doi: 10.1136/bmj.f108

59. Bai J, Wong FW, Bauman A, Mohsin M. Parity and pregnancy outcomes. Am J Obstet Gynecol. 2002; 186:2748.
60. Flenady V, Koopmans L, Middleton P, Frøen F, Smith GC, Gibbons K, et al. Major risk factors for stillbirth in high-income countries: a systematic review and meta-analysis. Lancet. 2011; 377:1331-40.

61. Schempf AH, Branum AM, Lukacs SL, Schoendorf KC. Maternal age and parity-associated risks of preterm birth: differences by race/ethnicity. Paediatr Perinat Epidemiol. 2007; 21:34-43. PubMed.

62. Kiely JL, Paneth N, Susser M. An assessment of the effects of maternal age and parity in different components of perinatal mortality. Am J Epidemiol. 1986; 123:444-54. PubMed.

63. Astolfi P, Zonta LA. Risks of preterm delivery and association with maternal age, birth order, and fetal gender. Hum Reprod. 1999;14:2891-4. PubMed.

64. Chan BC, Lao TT. Influence of parity on the obstetric performance of mothers aged 40 years and above. Hum Reprod. 1999;14:833-7. PubMed.

65. Lisonkova S, Patricia A. Janssen, Sam B. Sheps, Shoo K. Lee, Dahlgren L. The Effect of Maternal Age on Adverse Birth Outcomes: Does Parity Matter? J Obstet Gynaecol Can. 2010; 32(6):541-548.

66. World Health Organization (WHO). 2006b. Report of a WHO technical consultation on birth spacing. http:// www.who.int/making_pregnancy_safer/publications/ policy_brief_birth_spacing.pdf 